\title{
ORIGINAL ARTICLE Metabolic syndrome in young children: definitions and results of the IDEFICS study
}

\author{
W Ahrens ${ }^{1,2,13}$, LA Moreno ${ }^{3,13}$, S Mårild ${ }^{4}$, D Molnár ${ }^{5}$, A Siani ${ }^{6}$, S De Henauw ${ }^{7}$, J Böhmann ${ }^{8}$, K Günther $^{1}$, C Hadjigeorgiou ${ }^{9}$, \\ $\mathrm{L}_{\text {lacoviello }}{ }^{10}$, L Lissner ${ }^{11}$, T Veidebaum ${ }^{12}, \mathrm{H}$ Pohlabel ${ }^{1,14}$ and I Pigeot ${ }^{1,2,14}$ on behalf of the IDEFICS consortium
}

OBJECTIVE: To estimate the prevalence of the metabolic syndrome (MetS) using reference standards obtained in European children and to develop a quantitative MetS score and describe its distribution in children.

DESIGN AND METHODS: Population-based survey in eight European countries, including 18745 children 2.0 to 10.9 years, recruited during a second survey. Anthropometry (weight, height and waist circumference), blood pressure and serum-fasting triglycerides, HDL cholesterol, glucose and insulin were measured. We applied three widely accepted definitions of the pediatric MetS and we suggest a new definition, to guide pediatricians in decisions about close monitoring or even intervention (values of at least three of the MetS components exceeding the 90 th or 95th percentile, respectively). We used a $z$-score standardisation to calculate a continuous score combining the MetS components.

RESULTS: Among the various definitions of MetS, the highest prevalence (5.5\%) was obtained with our new definition requiring close observation (monitoring level). Our more conservative definition, requiring pediatric intervention gives a prevalence of $1.8 \%$. In general, prevalences were higher in girls than in boys. The prevalence of metabolic syndrome is highest among obese children. All definitions classify a small percentage of thin or normal weight children as being affected. The metabolic syndrome score shows a positive trend with age, particularly regarding the upper percentiles of the score.

CONCLUSIONS: According to different definitions of pediatric MetS, a non-negligible proportion of mostly prepubertal children are classified as affected. We propose a new definition of MetS that should improve clinical guidance. The continuous score developed may also serve as a useful tool in pediatric obesity research. It has to be noted, however, that the proposed cutoffs are based on a statistical definition that does not yet allow to quantify the risk of subsequent disease.

International Journal of Obesity (2014) 38, S4-S14; doi:10.1038/ijo.2014.130

\section{INTRODUCTION}

Cardiovascular diseases are one of the most common causes of mortality in developed countries. ${ }^{1}$ Several risk factors have been identified as major determinants of these diseases, like hypertension, dyslipidaemia, type 2 diabetes and smoking., ${ }^{2,3}$ Some of them, or their precursors, can already be identified in youth. ${ }^{4}$ Cardiovascular risk factors tend to cluster, not only in adults, but also in children. ${ }^{5,6}$ Factor analyses in children have shown that single risk factors can be grouped into 2 to 4 aggregate factors. ${ }^{7,8}$

The metabolic syndrome in adults is generally defined as a cluster of cardiovascular risk factors, namely central obesity, hyperglycaemia, dyslipidaemia and elevated blood pressure, which are often associated with a condition of insulin resistance. ${ }^{9,10}$

The metabolic syndrome has been already described in young populations. ${ }^{11}$ Several authors have reported the prevalence of the metabolic syndrome in children. ${ }^{12}$ However, there is no consensus about the definition of the metabolic syndrome in children. $^{13}$ This is mainly due to the fact that there are no reference values for the different components to be used during childhood. ${ }^{14}$ From this point of view, reference values provided by the IDEFICS (Identification and prevention of Dietary- and lifestyle-induced health Effects in Children and infantS) study ${ }^{15}$ of European children may allow us to classify children according to the different components of the syndrome (see Nagy et al., ${ }^{16}$ Barba et al., ${ }^{17}$ De Henauw et al., ${ }^{18}$ Peplies et al. ${ }^{19}$ this issue).

At the population level, another approach to address the clustering of cardiovascular risk factors is to compute a quantitative risk score. ${ }^{20}$ Pandit et al. ${ }^{21}$ found that a continuous metabolic syndrome score was a better tool to assess atherosclerotic risk in children than individual metabolic syndrome components, where that risk was assessed in terms of carotid intima-media thickness and vascular stiffness parameters as subclinical endpoints. Such risk scores were already used in different studies, mainly trying to identify their association with lifestyle risk factors, that is, dietary intake and physical activity. ${ }^{22-24}$

The aim of our study is to estimate the prevalence of the metabolic syndrome using reference standards obtained in

\footnotetext{
${ }^{1}$ Leibniz Institute for Prevention Research and Epidemiology_BIPS, Bremen, Germany; ${ }^{2}$ Institute of Statistics, Faculty of Mathematics and Computer Science, Bremen University, Bremen, Germany; ${ }^{3}$ GENUD (Growth, Exercise, Nutrition and Development) Research Group, University of Zaragoza, Zaragoza, Spain; ${ }^{4}$ Department of Paediatrics, Institute of Clinical Sciences, Sahlgrenska Academy, University of Gothenburg, Gothenburg, Sweden; ${ }^{5}$ Department of Paediatrics, Medical Faculty, University of Pécs, Pécs, Hungary; ${ }^{6}$ Institute of Food Sciences, Unit of Epidemiology \& Population Genetics, National Research Council, Avellino, Italy; ${ }^{7}$ Department of Public Health, Faculty of Medicine and Health Sciences, Ghent University, Ghent, Belgium; ${ }^{8}$ Paediatric Clinic Delmenhorst, Delmenhorst, Germany; ${ }^{9}$ Research and Education Institute of Child Health, Strovolos, Cyprus; ${ }^{10}$ Department of Epidemiology and Prevention, Unit of Molecular and Nutritional Epidemiology, IRCCS Istituto Neurologico Mediterraneo Neuromed, Pozzilli, Italy; ${ }^{11}$ Department of Public Health and Community Medicine, University of Gothenburg, Gothenburg, Sweden and ${ }^{12}$ National Institute for Health Development, Tallinn, Estonia. Correspondence: Professor Dr W Ahrens, Leibniz Institute for Prevention Research and Epidemiology—BIPS, Achterstrasse 30, Bremen D-28359, Germany.

E-mail: ahrens@bips.uni-bremen.de

${ }^{13}$ These authors contributed equally to this work.

${ }^{14}$ These authors share the senior authorship.
} 
healthy European children from the IDEFICS study. Based on the distribution of components of the metabolic syndrome in the IDEFICS cohort, we propose a new definition of the metabolic syndrome to guide pediatricians' decisions to conduct either close monitoring (monitoring level) or even an intervention (action level) in affected children. We also compare our results with those obtained using existing definitions of the metabolic syndrome in children. Finally, we develop a quantitative cardiovascular risk score and describe its distribution in our cohort of mostly prepubertal children.

\section{SUBJECTS AND METHODS}

Study subjects

A cohort of 16228 children aged 2-9 years was examined in a populationbased baseline survey in eight European countries ranging from North to South and from East to West (Sweden, Germany, Hungary, Italy, Cyprus, Spain, Belgium, Estonia) from autumn 2007 to spring 2008. While we recruited study subjects from typical regional population clusters in each country, the study was not designed to provide a nationally representative sample. Rather, this baseline survey $\left(T_{0}\right)$ was the starting point of the prospective study with the largest European children's cohort established to date. ${ }^{15}$ Together with an additional 2517 children aged $2.0-10.9$ years who were newly recruited during a second survey $\left(T_{1}\right) 2$ years later, this cohort formed the basis for the present analysis. Exactly the same survey modules were deployed at baseline $\left(T_{0}\right)$ and at follow-up $\left(T_{1}\right)$.

All children in the defined age group who resided in the study regions and who attended the selected primary schools (grades 1 and 2), preschools or kindergartens were eligible for participation. Children were approached via schools and kindergartens to facilitate equal enrolment of all social groups. In addition to the signed informed consent given by parents, each child was asked to give verbal assent immediately before examination.

Although all participants were asked to attend the study centre in the morning after an overnight fast for the blood draw and those examinations requiring a fasting status (for example, measurement of waist circumference), all children were asked whether they had eaten anything just before the examination. Those children who reported to be nonfasting were excluded from the analysis group. Thus our final analysis group consisted of at most 18169 children: the subsequent analyses are based on varying sample sizes depending on the measurement of interest as it was possible for children to opt out for certain modules of the examination.

\section{Questionnaires and examinations}

Parents filled in a self-completion questionnaire to assess gestational, behavioural and sociodemographic factors and a children's eating habits questionnaire on frequency of food consumption and dietary habits.

The examination programme included standard anthropometric measures, ${ }^{25}$ such as weight, height, skinfolds and waist circumference, clinical parameters such as blood pressure, collection of urine, saliva and blood for further medical parameters and genetic analyses, and accelerometry to assess physical activity. In this section, we describe the measurements that were considered in our analysis.

Anthropometry. Weight was measured with an electronic scale (Tanita BC 420 SMA, Tanita Europe $\mathrm{GmbH}$, Sindelfingen, Germany) to the nearest $0.1 \mathrm{~kg}$. The children wore only underwear and a T-shirt. Height was measured, barefoot, using a telescopic height measuring instrument (Seca 225 stadiometer, seca, Birmingham, UK) to the nearest $0.1 \mathrm{~cm}$. Body mass index was calculated as weight in kilograms divided by the square of the height in metres. Children were classified as normal weight, overweight or obese according to the cutoffs by the International Childhood Obesity Task Force, recently updated by Cole and Lobstein. ${ }^{26}$ Circumference measurements were taken at four sites: arm, waist, hip and neck with an inelastic tape (Seca 200). The measurement of waist circumference was obtained in upright position with relaxed abdomen and feet together, midway between the lowest rib margin and the iliac crest to the nearest $0.1 \mathrm{~cm}$ (see Nagy et al.; ${ }^{16}$ this issue).

Blood pressure. Blood pressure was measured with an automated oscillometric device (Welch Allyn 4200B-E2, Welch Allyn Inc., New York, NY, USA), ${ }^{27}$ according to a standardised procedure as described in
Barba et al. ${ }^{17}$ (this issue). The cuff length for blood pressure measurement was chosen according to the arm circumference value. ${ }^{28}$ Children were asked to sit for at least $5 \mathrm{~min}$ before measurement. Two records were taken, with 2-min interval in between, plus a further one in case of difference $>5 \%$ in blood pressure between the two previous readings. The average of the two (or three) measurements was used for statistical analysis.

Blood collection. We aimed to obtain fasting blood from all children via either venipuncture or capillary sampling. To ensure that basic data on metabolic disturbances were available for as many children as possible, a point-of-care analyser was used to assess blood glucose, HDL and LDL cholesterol and triglycerides in one drop of capillary blood from the fingertip on the spot. To avoid the finger prick in children who agreed to the venipuncture, one drop of venous blood was used for the point-of-care analysis. Blood was immediately transferred from the capillary tube to Cholestech LDX (Cholestech Corp.) ${ }^{29}$ test cassettes by capillary plungers. The Cholestech LDX measures total cholesterol and HDL cholesterol by the enzymatic method of Roeschlau and Allain, triglycerides by an enzymatic method based on the hydrolysis of triglycerides and glucose by an enzymatic method using glucose oxidase. The Cholestech LDX uses reflectance photometry to measure the analyte concentration. The analyser automatically calculates LDL cholesterol values. Point-of-care analysis was then done within $5 \mathrm{~min}$ of blood withdrawal. Blood samples were processed to separate serum/plasma and stored at $-80^{\circ} \mathrm{C}$. All blood, serum, urine and saliva samples were transferred to a central biorepository to coordinate the laboratory analyses and to ensure standardised storage and handling of samples. ${ }^{30}$ Serum insulin concentrations were measured by luminescence immunoassay in a central laboratory. We used an AUTO-GA Immulite 2000, Siemens, Eschborn, Germany. As a measure of insulin resistance, we used the homeostasis model assessment $(\text { HOMA-IR) })^{31}$ using fasting glucose and plasma insulin where HOMA-IR was calculated as fasting insulin $\left(\mu \mathrm{lU} \mathrm{ml}{ }^{-1}\right) \times$ fasting glucose $\left(\mathrm{mg} \mathrm{dl}^{-1}\right) / 405$ (see Peplies et al. ${ }^{19}$ this issue).

\section{Quality management}

All measurements followed detailed standard operation procedures. ${ }^{32}$ Field personnel from each study centre participated in central training and organised local training sessions thereafter. Adherence of field staff to the standard operation procedures was checked during on-site visits. Questionnaires were developed in English, translated to local languages and then back-translated to check for translation errors. All study centres used the same technical equipment. Databases and computer-assisted questionnaires included automated plausibility checks. All numerical variables were entered twice independently. To further check for the quality of data, subsamples of study subjects were examined repeatedly to calculate the inter- and intra-observer reliability of anthropometric measurements. ${ }^{33}$

\section{Definition of metabolic syndrome}

We applied three commonly used definitions ${ }^{34-36}$ of the pediatric metabolic syndrome (MetS) to create the analysis groups for our statistical analyses. The definition by Cook et al. ${ }^{34}$ corresponds to the NCEP (National Cholesterol Education Program) definition adapted to adolescents. It may thus not be appropriate for smaller children, but it is the most widely used definition in pediatric practice. We did not consider the definitions suggested by the WHO (World Health Organisation) and its modified version for nondiabetic subjects by EGIR (Group for the Study of Insulin Resistance) as they are provided for adults only with no adaptation for children. The IDF (International Diabetes Federation) provided a definition of MetS adapted for children which we used. ${ }^{36}$ The definition by Viner et al. $^{35}$ is based on only 103 obese children from UK and adolescents of different ethnicities to identify a high-risk group among the obese. However, it is a widely accepted definition, which is frequently used by physicians. In addition, it is the only one including serum-fasting insulin, a key component of the metabolic syndrome, especially at early stages.

Each of the three definitions we selected has its limitations but there are reasons to see them as the best currently on offer. They are summarised in Table 1 and compared with the new definitions we propose. Each of them considers the following four major cardiovascular risk factors used for defining MetS in adults: (1) excess adiposity, (2) blood pressure, (3) blood lipids and (4) blood glucose/insulin, ${ }^{13}$ which are components of the metabolic syndrome. According to these definitions, a child is diagnosed 
Table 1. Definitions of pediatric metabolic syndrome

\begin{tabular}{|c|c|c|c|c|}
\hline Definition & $\begin{array}{l}\text { Excess } \\
\text { adiposity }\end{array}$ & Blood pressure & Blood lipids & Blood glucose/insulin \\
\hline Cook et al. ${ }^{34}$ & $\begin{array}{l}\text { WC } \geqslant 90 \text { th } \\
\text { percentile }\end{array}$ & $\begin{array}{l}\text { SBP or DBP } \\
\text { percentile }\end{array}$ & $\begin{array}{l}\text { Triglycerides } \geqslant 1.24 \mathrm{mmoll}^{-1}\left(110 \mathrm{mg} \mathrm{dl}^{-1}\right) \text { or HDL cholesterol } \\
\leqslant 1.03 \mathrm{mmol} \mathrm{I}^{-1}\left(40 \mathrm{mg} \mathrm{dl}^{-1}\right)\end{array}$ & $\begin{array}{l}\text { Impaired fasting glucose } \geqslant 6.11 \mathrm{mmol} \mathrm{I}^{-1} \\
\left(110 \mathrm{mg} \mathrm{dl}^{-1}\right)\end{array}$ \\
\hline Viner et al. $^{35}$ & $\begin{array}{l}\text { BMI } \geqslant 95 \text { th } \\
\text { percentile }^{38}\end{array}$ & SBP $\geqslant 95$ th percentile ${ }^{28}$ & $\begin{array}{l}\text { Triglycerides } \geqslant 1.69 \mathrm{mmol} \mathrm{I}^{-1}\left(150 \mathrm{mg} \mathrm{dl}^{-1}\right) \text { or } \mathrm{HDL} \text { cholesterol } \\
<0.91 \mathrm{mmol} \mathrm{I}^{-1}\left(35 \mathrm{mg} \mathrm{dl}^{-1}\right) \text { or high total cholesterol } \geqslant 95 \mathrm{th} \\
\text { percentile }\end{array}$ & $\begin{array}{l}\text { Hyperinsulinaemia } \geqslant 104.2 \mathrm{pmoll}^{-1}\left(15 \mathrm{mU} \mathrm{I}^{-1}\right) \\
\text { or impaired fasting glucose } \geqslant 6.11 \mathrm{mmoll}^{-1} \\
\left(110 \mathrm{mg} \mathrm{dl}^{-1}\right)\end{array}$ \\
\hline IDF $^{36}$ & $\begin{array}{l}\text { WC } \geqslant 90 \text { th } \\
\text { percentile }\end{array}$ & $\begin{array}{l}\mathrm{SBP} \geqslant 17.3 \mathrm{kPa} \\
(130 \mathrm{~mm} \mathrm{Hg}) \text { or DBP } \\
\geqslant 11.3 \mathrm{kPa}(85 \mathrm{~mm} \mathrm{Hg})\end{array}$ & $\begin{array}{l}\text { Triglycerides } \geqslant 1.69 \mathrm{mmoll}^{-1}\left(150 \mathrm{mg} \mathrm{dl}^{-1}\right) \text { or HDL cholesterol } \\
<1.03 \mathrm{mmol} \mathrm{I}^{-1}\left(40 \mathrm{mg} \mathrm{dl}^{-1}\right)\end{array}$ & $\begin{array}{l}\text { Impaired fasting glucose } \geqslant 5.55 \mathrm{mmol}^{-1} \\
\left(100 \mathrm{mg} \mathrm{dl}^{-1}\right)\end{array}$ \\
\hline $\begin{array}{l}\text { IDEFICS }^{14} \\
\text {-monitoring }\end{array}$ & $\begin{array}{l}\text { WC } \geqslant 90 \text { th } \\
\text { percentile }\end{array}$ & $\begin{array}{l}\text { SBP } \geqslant 90 \text { th percentile } \\
\text { DBP } \geqslant 90 \text { th } \text { percentile }^{17}\end{array}$ & $\begin{array}{l}\text { Triglycerides } \geqslant 90 \text { th percentile }{ }^{18} \text { or HDL cholesterol } \leqslant 10 \text { th } \\
\text { percentile }^{18}\end{array}$ & $\begin{array}{l}\text { HOMA-insulin resistance } \geqslant 90 \text { th percentile }{ }^{19} \text { or } \\
\text { fasting glucose } \geqslant 90 \text { th percentile }\end{array}$ \\
\hline
\end{tabular}

level

Abbreviations: BMI, body mass index; DBP, diastolic blood pressure; HDL, high-density lipoprotein; IDEFICS, Identification and prevention of Dietary- and lifestyle-induced health Effects in Children and infantS; IDF, International Diabetes Federation; SBP, systolic blood pressure; WC, waist circumference. ${ }^{a}$ At least one of both variables had to be available.

with MetS if a predefined critical value is exceeded for three or more of these risk factors. Based on the most recent age-specific percentiles derived for these risk factors from the IDEFICS study, we suggest an updated definition of the pediatric MetS, which is also given in Table 1. As we observed an effect of age and sex on all components of MetS, we considered age- and sex-specific percentiles for each of them. We have considered the same components using two different cutoffs, to guide pediatricians in deciding whether close monitoring is appropriate (values of at least three of the components of MetS exceeding the 90th percentile) or even an intervention (values of at least three of the components of MetS exceeding the 95th percentile) in affected children.

\section{Definition of the metabolic syndrome score}

Following a similar approach as Eisenmann, ${ }^{20}$ we used a $z$-score standardisation to calculate a continuous score that combines the components used to define MetS in adults, that is, waist circumference, blood pressure, dyslipidaemia and hyperglycaemia. The additive score is defined as the sum of sex- and age-specific $z$-scores of waist circumference and HOMA index. A higher score indicates a less-favourable metabolic profile. Instead of using the mean arterial pressure we added the mean of the $z$-scores of diastolic and systolic blood pressure to this additive MetS score. Eisenmann included the $z$-scores of HDL-C and triglycerides as two separate components of the total score, whereas, we calculated the mean of the sex- and age-specific z-scores of HDL-C (multiplied with - 1, due to the inverse association between $\mathrm{HDL}-\mathrm{C}$ and the metabolic risk profile) and triglycerides and added this mean $z$-score to the total MetS score. In this way, dyslipidaemia receives the same weight as the other three components in our definition of the MetS score. Four examples illustrating the calculation of the MetS score are given for arbitrarily chosen children in Appendix A in analogy to Eisenmann. ${ }^{20}$

Sex- and age-specific $z$-scores (that is, standardised residuals) were calculated based on GAMLSS models of the corresponding variables, that is, waist circumference (see Nagy et al. ${ }^{16}$ this issue) and HOMA (see Peplies et al. ${ }^{19}$ this issue) based on the Box-Cox t distribution and HDL-C (see De Henauw et al.; ${ }^{18}$ this issue) based on the Box-Cox-Power-Exponential distribution. Z-scores of blood pressure were calculated as sex-, age-, and height-specific values based on a Box-Cox t distribution (see Barba et al.; ${ }^{17}$ this issue).

Triglycerides were measured with a detection limit of $0.51 \mathrm{mmol}^{-1}$ $\left(45 \mathrm{mg} \mathrm{dl}^{-1}\right)$. Measurements in $55.9 \%$ of boys and $46.8 \%$ of girls fell below this detection limit. Thus the distribution of triglycerides was strongly skewed and available distributions in the gamlss package could not be fitted accurately. Hence, based on the uniform distribution, triglyceride values below $0.51 \mathrm{mmol} \mathrm{I}^{-1}\left(45 \mathrm{mg} \mathrm{dl}^{-1}\right)$ were repeatedly randomised to values between 0.51 and $0.19 \mathrm{mmoll}^{-1}\left(45-17 \mathrm{mg} \mathrm{dl}^{-1}\right)$, which was the lowest reported value found for school children. ${ }^{40}$ These simulated data were combined with the measured values to create one data set that was then used to fit a statistical model describing these data best. Sensitivity analyses showed that the resulting model was quite robust against the choice of the distribution used for the simulation of values below the detection limit. The final model for boys and girls is based on a Box-Cox Cole and Green distribution without age effects, that is, $\mu, \log (\sigma)$ and $v$ were modelled as constant. As a result, sex-specific but not age-specific $z$-scores were calculated for triglycerides.

\section{Statistical analysis}

We applied each of the widely accepted definitions summarised in Table 1 as well as our own characterisation of pediatric metabolic syndrome to the IDEFICS data set and calculated sex-specific prevalences, stratified by weight status (thinness/normal weight, overweight, obesity) according to Cole and Lobstein. ${ }^{26}$ The degree of agreement between the diagnostic criteria of Cook et al., ${ }^{34}$ Viner et al., ${ }^{35}$ Zimmet el al. ${ }^{36}$ and our own suggestions was quantified by kappa statistics (reported with 95\% confidence limits). To assess the degree of agreement, we had to restrict the database to children with complete data with respect to each of the four definitions of metabolic syndrome which led to reduction of the overall sample size to $N=12319$.

We calculated percentile curves of the continuous MetS as a function of age stratified by sex using the GAMLSS method as an extension of the LMS method. The LMS method models three parameters: the skewness (L) accounts for the deviation from a normal distribution using a Box-Cox transformation, the median $(\mathrm{M})$ the outcome variable depending on one explanatory variable, and the coefficient of variation (S) accounts for the variation of data points around the mean and adjusts for nonuniform dispersion. The GAMLSS method is able to model more than one covariate and to consider other distributions. We used the gamlss package (version 4.2-6) of the statistical software $\mathrm{R}$ (version 3.0.1). ${ }^{41}$ Different distributions, that is, the Box-Cox-Power-Exponential, Box-Cox t, Box-Cox Cole and Green and normal distribution were fitted to the observed distribution of MetS. Moreover, the influence of age on parameters of the considered distributions were modelled either as a constant, as a linear function or as a cubic spline of the covariates.

Goodness of fit was assessed by the Bayesian Information Criterion and $\mathrm{Q}-\mathrm{Q}$ plots to select the final model including the fitted distribution of MetS and the influence of the covariates on distribution parameters. Finally, curves for the 1st, 3rd, 5th, 10th, 25th, 50th, 75th, 90th, 97th and 99th percentiles were calculated based on the model that showed the best goodness of fit. ${ }^{41,42}$ The best model for MetS in boys and girls consists of a Box-Cox Cole and Green distribution with parameters modelled as follows: $\mu$ and $\log (\sigma)$ linearly and $v$ as a constant. Due to missing values for the HOMA index, we had to restrict our analyses on the continuous total MetS score to $N=7668$ children.

\section{RESULTS}

Table 2 shows the prevalence of the metabolic syndrome (MetS) according to the various definitions given in Table 1 stratified by sex and by weight category. The new definition which we suggest as corresponding to a need for close observation of an affected child (monitoring level) leads to the highest prevalence $(5.5 \%)$, whereas the definition proposed by the IDF Consensus Group ${ }^{36}$ results in the lowest prevalence $(0.4 \%)$. The more conservative definition we propose for deciding which children may merit pediatric intervention (action level) gives an overall prevalence of $1.8 \%$, which is slightly higher than the prevalences resulting from the definitions by Cook et al. ${ }^{34}(1.4 \%)$ and Viner et al. ${ }^{35}$ $(0.9 \%)$. Except for the IDF definition, ${ }^{36}$ the prevalences tend to be higher in girls as compared with boys. The most pronounced sex 
Table 2. Prevalence of pediatric metabolic syndrome (MetS; three or more characteristics present) according to the definitions in Table 1 in fasting normal weight/thin, overweight and obese children

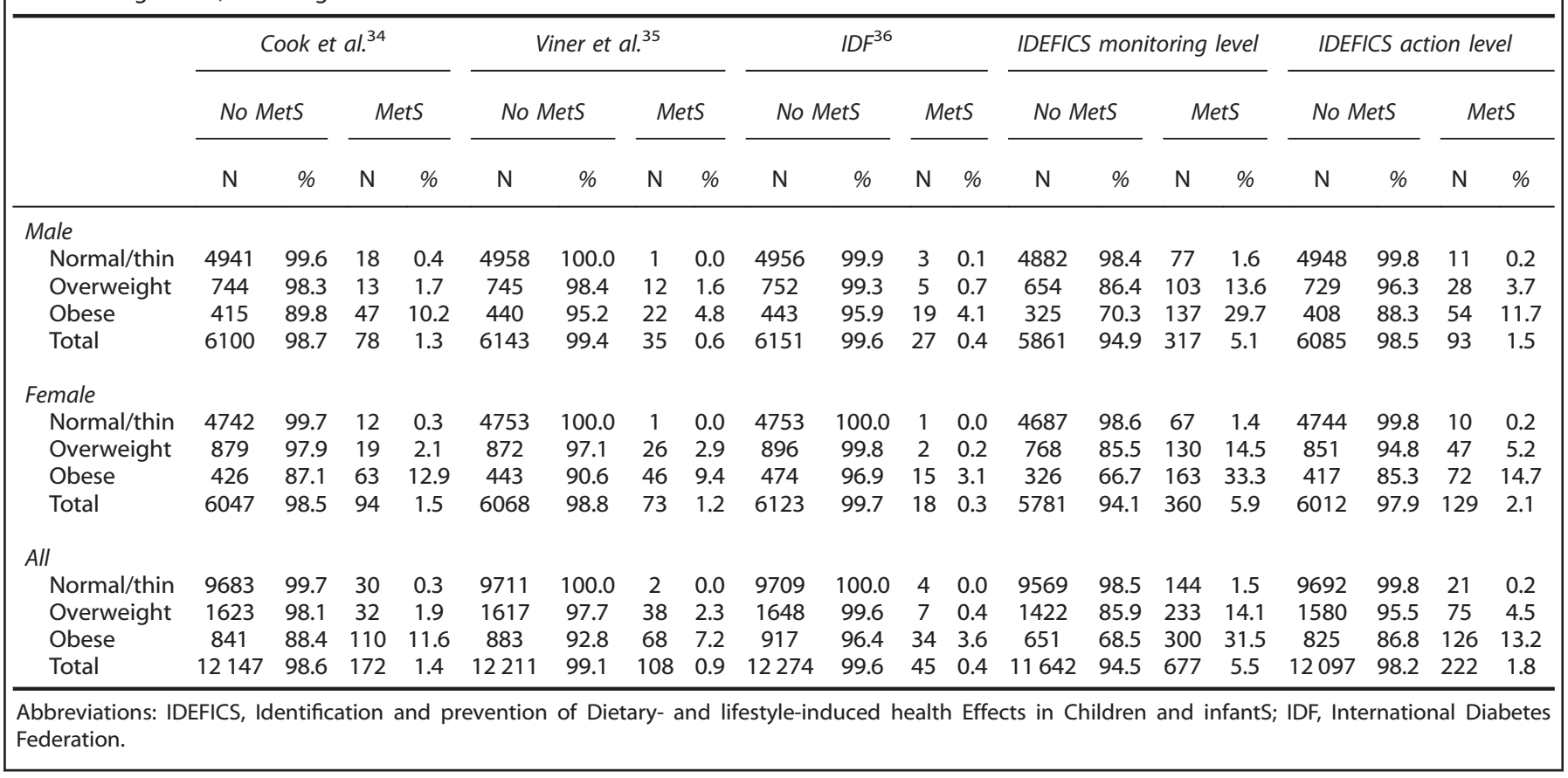

difference is observed for the definition by Viner et al. where the prevalence is twice as high in girls (1.2\%) as compared with boys (0.6\%). All definitions classify a small percentage of thin or normal weight children as being affected by the metabolic syndrome. The prevalence of MetS increases with weight category and is highest among obese children according to all definitions.

The contribution of the various components used for the definition of the metabolic syndrome varies substantially between the different definitions. This is illustrated in Figure 1 and Table 3. The cutoffs proposed by Cook et al..$^{34}$ and Viner et al. ${ }^{35}$ result in a near-negligible number of children classified as hyperglycaemic. Thus, in both definitions, glucose and/or insulin levels have only a minor role as children exceeding the proposed limits only contribute a very small proportion to the prevalence of MetS. The same is true for the role of blood pressure in the definition proposed by the IDF Consensus Group, ${ }^{36}$ where the cutoff is exceeded by only a very small fraction of children.

The proportion of children exceeding the cutoffs empirically proposed on the basis of the distribution in the IDEFICS cohort shows more similar proportions for the different components of the MetS. No component shows extremely low prevalences, giving about equal chances for each of them to contribute to the overall prevalence of the MetS in our sample. Although in the definition by Cook et al., ${ }^{34}$ almost $85 \%$ of all children with MetS are classified by the same three components, that is, adiposity, hypertension and dyslipidaemia, in both definitions we propose, adiposity plus any combination of the remaining three components are needed to reach this proportion (Table 3). The component that shows the greatest independent likelihood of classifying a child as being affected is dyslipidaemia in all the three existing definitions, ${ }^{34-36}$ whereas it is waist circumference in our definitions.

The degree of agreement between the various definitions is limited. Besides the good agreement between both definitions we propose, the second best agreement is observed between our conservative definition (action level) and the one proposed by Viner et al. ${ }^{35}$ (Table 4). According to Landis and Koch, ${ }^{43}$ this agreement would be classified as 'moderate' (0.41-0.60) whereas all other kappa values would be rated as indicating either 'fair'
(0.21-0.40) or only 'slight' (0-0.20) agreement. The lowest agreement is observed in comparison with the definition proposed by the IDF Consensus Group. ${ }^{36}$ In turn, this shows the best agreement with the definition of Cook et al. $^{34}$ and the weakest with the monitoring level definition proposed by us.

Although age-specific cutoffs were used to define metabolic syndrome in children, some definitions show a higher prevalence of MetS in older children whereas others do not. Regarding the IDF definition, there is only a negligible difference in prevalence between preschool children up to 5.9 years old (prevalence $=0.3 \%$ ) and primary school children (6.0-10.9 years; prevalence $=0.4 \%$ ). According to the definition by Cook et al., ${ }^{34}$ the prevalence is $1.4 \%$ in both. The definition of Viner et al. ${ }^{35}$ results in a prevalence, which is substantially lower in preschool children $(0.3 \%)$ as compared with school-aged children (1.3\%). A similar difference is observed with both of our definitions, which result in prevalences of 3.4 vs $6.8 \%$ and 0.8 vs $2.5 \%$, respectively. These age similarities and differences run in parallel in both sexes.

The classification of an individual child according to any of these definitions is complex because it requires the simultaneous consideration of the age- and sex-specific cutoff values for all its components. In our definition this is further complicated by the fact, that the blood pressure cutoffs have to consider body height in addition to age and sex. To facilitate this calculation we offer a simple web application where the individual measurement values may be entered to obtain the percentiles and the classification of an individual based on the data of the IDEFICS cohort (www. ideficsstudy.eu). An approximation of this classification is possible by looking up the age- and sex-specific percentile values given in Appendix B and applying the definitions given in Table 1 for the IDEFICS monitoring and action levels, respectively. The true classification can only be approximated by using this Appendix as blood pressure values are not stratified by body height.

Figure 2 and Table 5 show the age- and sex-specific percentile values of the metabolic syndrome score that was derived from the distribution of blood pressure, blood lipids, waist circumference and HOMA-IR of the IDEFICS cohort. On average, the score shows a positive trend with age, particularly in the upper percentiles. The 

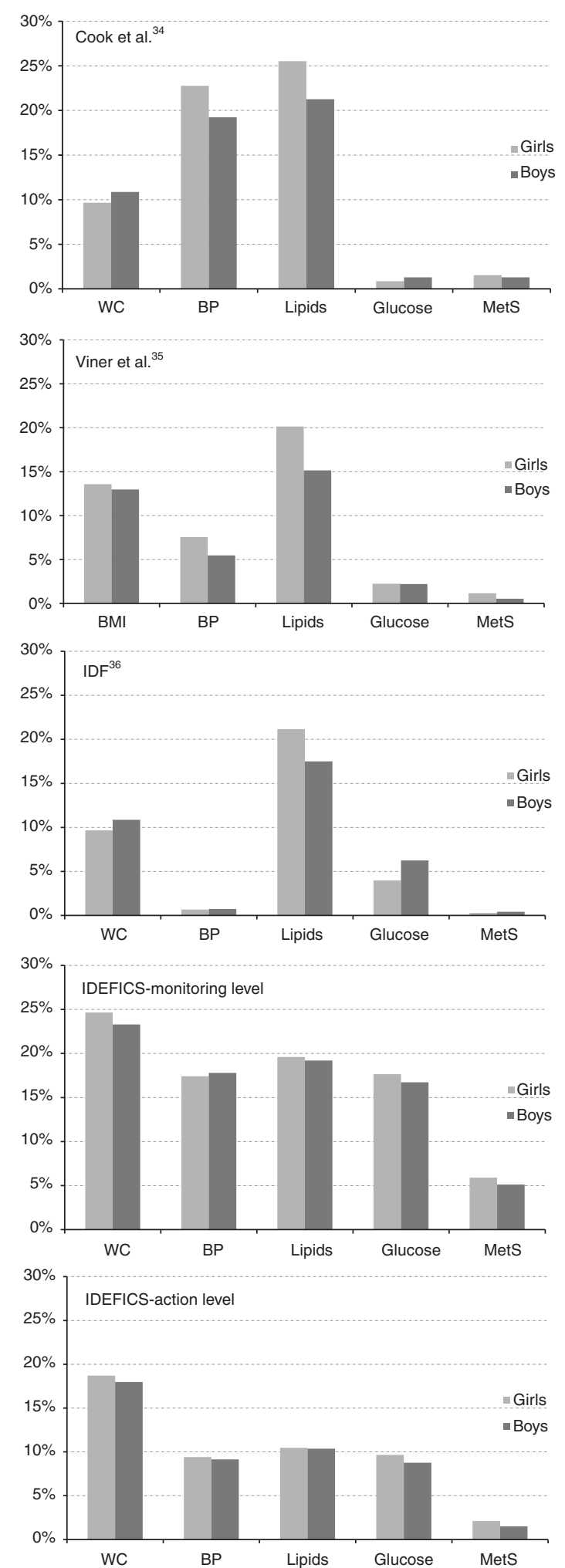

Figure 1. Prevalence of individual components of the metabolic syndrome (MetS) and of MetS in boys and girls according to five different definitions of MetS (cf. Table 1); BMI, body mass index; $\mathrm{BP}$, blood pressure; IDEFICS, Identification and prevention of Dietary- and lifestyle-induced health Effects in Children and infantS; WC, waist circumference. lowest percentiles show no age trend in boys whereas they show a negative trend in girls. Overall, this figure corresponds to the observation of a positive trend of the prevalence of MetS in preadolescent children. But it also reveals a higher variation of the parameter values contributing to the metabolic syndrome in older as compared with younger children.

\section{DISCUSSION}

Based on the cardiovascular risk factor profile obtained from a large population-based European cohort of healthy children aged 2.0-10.9 years, we propose a new definition of pediatric metabolic syndrome. Previous definitions show a low degree of agreement in classifying children as being affected by the metabolic syndrome. This is due to the fact that they use heterogeneous and often arbitrary cutoffs for the components when defining pediatric metabolic syndrome, resulting in different weightings for the components. Our approach is more consistent in that it uses sex- and age-specific cutoffs based on the distribution of all MetS components in healthy children. This leads to a more balanced contribution of the single components to the overall prevalence of MetS in children. In fact, previous definitions of MetS, when applied to pre-adolescent children, mostly rely on only three of the four generally accepted components of this syndrome. In the definitions of Cook et al. ${ }^{34}$ and Viner et al., ${ }^{35}$ hyperglycaemia has only a minor role, whereas the definition of the IDF fails to take elevated blood pressure into account. This may suggest limitations in the existing definitions, most likely because they are either based on selected populations like obese subjects or not specifically derived for pre-adolescent children. In contrast, the definition we propose, while giving particular weighting to waist circumference, gives roughly equal weight to the other three components in classifying children as being affected by the metabolic syndrome.

When we apply the three existing definitions, the prevalence of MetS in a large population-based sample of European children comprising the whole IDEFICS cohort varies between $0.3 \%\left(\right.$ IDF $\left.^{36}\right)$ and $1.5 \%\left(\right.$ Cook et al. $\left.{ }^{34}\right)$ in girls and between $0.4 \%\left(\right.$ IDF $\left.^{36}\right)$ and $1.3 \%$ (Cook et al. $^{34}$ ) in boys. In our definition, we propose two decision levels to guide clinical practice where the first level may be considered as a level of concern requiring close observation of affected children (monitoring level) and the second level may call for an intervention to ameliorate the risk profile of affected children (action level). Based on the second level of our definition, we observe a prevalence of $2.1 \%$ in girls and $1.5 \%$ in boys. The corresponding prevalence based on the monitoring level is 5.9\% in girls and $5.1 \%$ in boys. As a consequence, 3.8\% girls and $3.6 \%$ boys should be monitored closely with regard to a potential worsening of their risk profile.

Comparing the prevalences obtained by existing definitions with the results from population-based studies in children with a similar age and using the same definitions, it seems that the prevalence in our population lies well in the range of previous data. In a population-based cohort study ${ }^{44}$ conducted in 10 and 15 years old youth from Estonia, Denmark and Portugal, the prevalence of MetS, using the criteria of the IDF Consensus Group, ${ }^{36}$ was 0.2 and $1.4 \%$ in 10 - and 15-year-old children, respectively, which compares with $0.4 \%$ in our sample of children with the majority of them being younger. In a study of 7-9-yearold children from Kansas (US), ${ }^{45}$ the prevalence was $5 \%$ according to the cutoffs by Cook et al. ${ }^{34}$ which is substantially higher than the prevalence of $1.4 \%$ observed in our cohort when we apply the same definition. Further studies reporting prevalences of MetS in clinical populations and/or adolescents ${ }^{34}$ are not considered here.

For any of the definitions of MetS, a clear positive gradient is seen across weight categories. As expected, by far most of the children in the obese category are classified as being affected. But even in the normal weight/thin category, a small fraction of 
Table 3. Proportions of different combinations of components of MetS according to the definitions given in Table 1

\begin{tabular}{|c|c|c|c|c|c|c|c|c|c|c|}
\hline \multirow[t]{2}{*}{ Combination } & \multicolumn{2}{|c|}{ Cook et al. ${ }^{34}$} & \multicolumn{2}{|c|}{ Viner et al. ${ }^{35}$} & \multicolumn{2}{|c|}{$I D F^{36}$} & \multicolumn{2}{|c|}{ IDEFICS monitoring level } & \multicolumn{2}{|c|}{ IDEFICS action level } \\
\hline & $\mathrm{N}$ & $\%$ & $\mathrm{~N}$ & $\%$ & $\mathrm{~N}$ & $\%$ & $\mathrm{~N}$ & $\%$ & $\mathrm{~N}$ & $\%$ \\
\hline AD+ BP+ Lipids - Glucose+ & 6 & 3.5 & 10 & 9.3 & 4 & 8.9 & 171 & 25.3 & 60 & 27.0 \\
\hline AD+ BP+ Lipids+ Glucose - & 142 & 82.6 & 57 & 52.8 & 13 & 28.9 & 155 & 22.9 & 43 & 19.4 \\
\hline AD+ BP+ Lipids+ Glucose+ & 4 & 2.3 & 6 & 5.6 & 2 & 4.4 & 97 & 14.3 & 25 & 11.3 \\
\hline
\end{tabular}

Table 4. Agreement of the various definitions of the metabolic syndrome (kappa) based on $N=12319$ children with a complete set of measurements

\begin{tabular}{|c|c|c|c|c|c|c|c|c|}
\hline & \multicolumn{2}{|c|}{ Viner et al. } & \multicolumn{2}{|c|}{ IDF } & \multicolumn{2}{|c|}{ IDEFICS monitoring level } & \multicolumn{2}{|c|}{ IDEFICS action level } \\
\hline & Kappa & $(95 \%$ Cl) & Kappa & $(95 \%$ Cl) & Kappa & $(95 \% C l)$ & Kappa & $(95 \%$ Cl) \\
\hline Cook et al. ${ }^{34}$ & 0.34 & $(0.26-0.41)$ & 0.25 & $(0.18-0.33)$ & 0.29 & $(0.25-0.33)$ & 0.35 & $(0.28-0.41)$ \\
\hline Viner et al. $^{35}$ & & & 0.18 & $(0.10-0.26)$ & 0.23 & $(0.19-0.27)$ & 0.46 & $(0.39-0.53)$ \\
\hline $\mathrm{IDF}^{36}$ & & & & & 0.11 & $(0.08-0.14)$ & 0.19 & $(0.13-0.25)$ \\
\hline IDEFICS monitoring level & & & & & & & 0.48 & $(0.44-0.52)$ \\
\hline
\end{tabular}

Abbreviations: $\mathrm{Cl}$, confidence interval; IDEFICS, Identification and prevention of Dietary- and lifestyle-induced health Effects in Children and infantS; IDF, International Diabetes Federation.
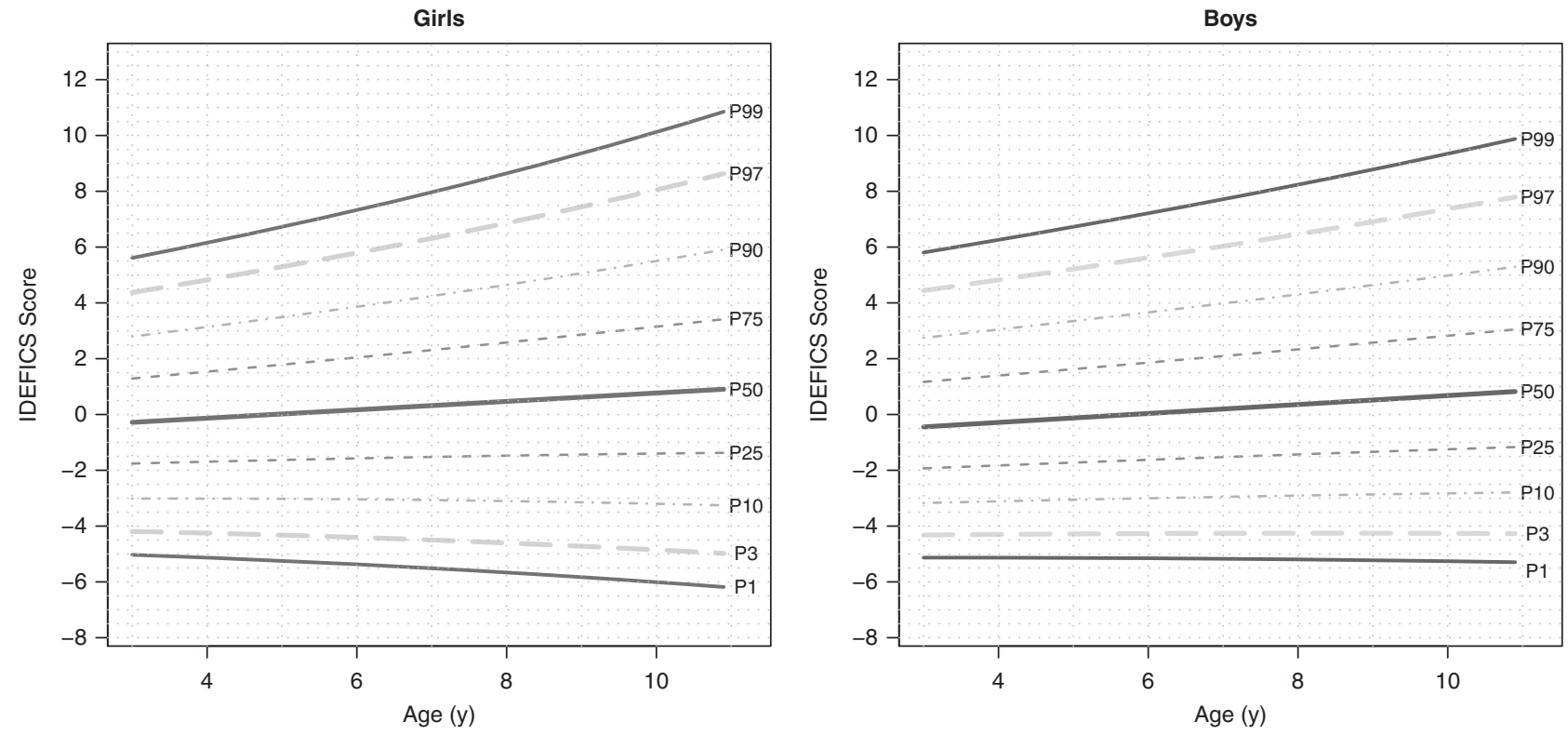

Figure 2. Age-specific percentiles of the IDEFICS metabolic syndrome score for girls (left) and boys (right). IDEFICS, Identification and prevention of Dietary- and lifestyle-induced health Effects in Children and infantS.

children is classified as being affected. This reflects the fact that the components considered for the definition of MetS have a continuous physiological distribution, which does not always follow the weight status. Just as there are overweight or obese children who seem to present with a normal metabolic risk profile, if judged on the basis of the classical MetS components, there are also normal weight children who are developing an unfavourable metabolic profile. ${ }^{46}$ We should also keep in mind that the body mass index, which is used to define the weight categories, reflects both fat and fat-free mass, as discussed in Nagy et al. ${ }^{16}$ (this issue). This gradient seems to continue even within the obese category as observed by Sen et al. ${ }^{47}$ who report a twofold increase of MetS 


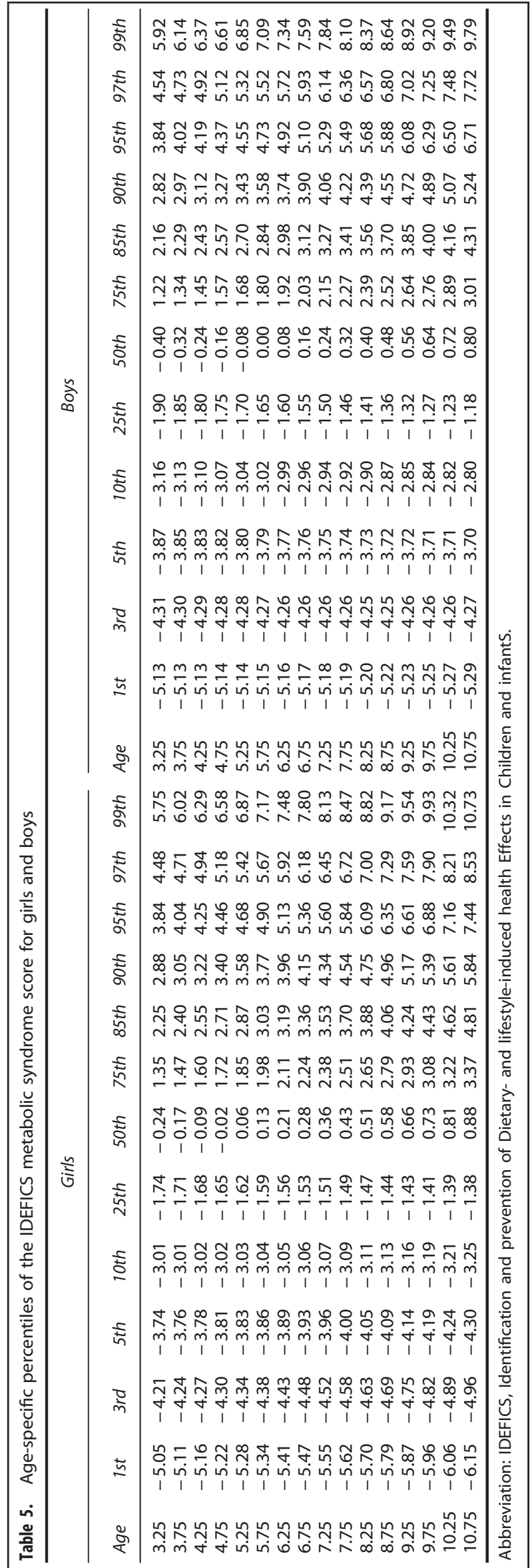

prevalence per one-point increase in body mass index $z$-score in 352 obese children (2-19 years of age) referred to a children's hospital. Thus the gradient of MetS prevalence observed across the three weight categories is plausible. ${ }^{48}$

According to most definitions, the prevalence of MetS is higher among girls than boys. But this difference seems to be slight. Observed differences by sex may depend on the cutoffs and components used in defining MetS-for example, with the IDF definition, the prevalence of MetS is slightly higher in boys than in girls. Using the same definition, Ekelund et al. ${ }^{44}$ also report a higher prevalence of MetS in boys. Sex differences may also vary by age. Using their own definition, Cook et al. $^{34}$ observed a higher prevalence of MetS in adolescent boys as compared with adolescent girls.

The prevalence of the risk factors postulated to contribute to the MetS varies substantially with the cutoffs used (cf. Figure 1). Likewise, the weight given to the different components of the MetS differs by definition. The cutoffs chosen by Cook et al. ${ }^{34}$ and Viner et al. $^{35}$ for glucose/insulin levels are so high that only a very small number of children exceed the threshold. Consequently, the prevalence of MetS is mainly driven by the other three components in these two definitions. The IDF definition, however, uses particularly high cutoffs for blood pressure, which are the ones defined for adults. Here, blood pressure contributes to a negligible proportion of children classified according to IDF as being affected by the MetS. In fact, all the three existing definitions tend to classify children based on only three out of the four components of MetS. This is not the case for the classification we propose on the basis of the IDEFICS cohort where each factor-with the exception of adiposity - has about equal chances to contribute to the overall prevalence of the MetS. It is therefore not surprising that our definition results in higher prevalences than the existing definitions.

As long as we have no clear evidence that one or more of the components poses greater risks of cardiometabolic disorders later in life, it seems reasonable to use a definition that assigns roughly equal weights to each of them. Magnussen et al. ${ }^{49}$ assessed the contribution of the risk factors included in the definition of MetS on the basis of two population-based prospective studies. They observed a stronger effect of overweight/obesity during childhood on carotid intima-media thickness and type 2 diabetes at 24-41 years of age as compared with the other factors. On this background it makes sense that adiposity receives the highest weight in the definition that we propose.

In general, the agreement between the various definitions assessed by the kappa coefficient in our cohort may be considered as slight to moderate. The agreement is mainly limited by two factors: (1) the great differences of the MetS prevalences and (2) the different weights given to single components of the MetS. Disregarding the agreement between the two definitions we propose, the highest kappa coefficient is observed for the definition by Viner et $a l^{35}$ and the IDEFICS action level. This may be due to the more balanced consideration of all four components by Viner et $a l .^{35}$ compared with the other two previous definitions. A low agreement was also observed in a sample of preadolescents girls between the definition adopted from the National Cholesterol Education Program Adult Treatment Panel III and the one adopted from the World Health Organisation. ${ }^{50}$

The comparisons presented here apply different definitions to the same data such that the laboratory assay used does not affect comparability. This may not be the case when data from other studies using different assays are to be compared with our results. It should be noted in this context that all laboratory analyses were done in a central certified clinical laboratory participating in quality control routines according to the standards of good laboratory practice. The glucose and lipid measurements obtained by the Colestech point-of-care analyser had previously shown to be in excellent agreement with the corresponding laboratory 
methods (see Peplies et al.; ${ }^{19}$ this issue). Particularly HOMA and insulin values may only be applicable to our reference values if comparable assays were used. Pediatricians using other assays may want to consider this caveat when referring to our z-scores.

We recognise that the most desirable way to define MetS would be in terms of a health-based criterion to define a cutoff above which the risk of future disease increases to a relevant and quantifiable degree. In the absence of such information, however, we believe the best option is to work with a statistical definition using plausible percentile values to define cutoffs. It is for this reason that we have chosen to propose criteria corresponding to two different levels of concern. Defining the metabolic syndrome in children by a single cutoff above which all children are considered as affected and below which all children are considered as healthy may be problematic. On one hand our proposal of two definitions, one for monitoring and a more restrictive one for action is a pragmatic way to address a problem inherent in conditions which lie on continuous distributions. On the other hand, both in the preventive and clinical settings, there is no other way to define a given condition at the individual and population level than to use cutoffs. Although they are not based on biological evidence, we believe that the proposed cutoffs are reasonable and useful for daily practice, because they reflect the most widely used cutoffs to define the various components of the MetS.

Rather than simply dichotomising the population into healthy (no MetS) and unhealthy (MetS) children using an arbitrary cutoff, the MetS score provides a more 'physiological' variable that accounts for the gradual changes and thus better reflects the continuum between a (putatively) unhealthy and a healthy metabolic profile. Such a continuous variable is particularly useful for research purposes and the evaluation of interventions. Used as an outcome variable in the investigation of detrimental or preventive effect of an exposure on children's health, it is much more powerful than a simple binary variable in detecting possible associations. ${ }^{20}$ Our additive MetS score follows the approach by Eisenmann ${ }^{20}$ to standardise the distribution of each of the four parameters included. For children we have no reliable data with regard to the relative impact of each component on the incidence of cardiovascular and metabolic diseases later in life. As argued before, given this lack of knowledge with regard to the predictive value of each component of the metabolic syndrome, it seems to be the best decision to assign equal weights to each parameter. This is assured by our statistical approach. A further strength of our score is the fact that it accounts for the age- and sex-specific distribution of its parameters and that the parameter estimates are valid for a large, heterogeneous and unselected population of healthy pre-adolescent children. However, the score also has some limitations. The parameter values included in the score are population-specific. Especially smaller populations may reveal different distributions and it is therefore desirable to provide data for the calculation of the MetS score in individuals or other populations using a large and diverse sample as ours as reference. To accomplish this, the authors will provide the necessary data as online material for use in other studies.

As discussed above, the main limitation of our approach is the lack of a clinically relevant, prospective outcome that would allow to assess the disease risk in relation to our definition of the metabolic syndrome or its single components. However, there are some results showing an association between metabolic syndrome and its components during childhood and the risk of contracting cardiometabolic disorders in adulthood. ${ }^{49,51}$

Another arguable limitation of our study is our cohort data involves only one measurement at a single point in time (or two or three measurements taken $x$ min apart, in the case of blood pressure) of the physiological markers considered here, when these markers in fact show substantial day-to-day variations. This is, of course, important for the individual diagnosis done by a pediatrician and it is recommended to evaluate a child only on the basis of repeated measurements. On the population level, however, such variations should not have an impact on the overall prevalence estimates.

Like others, we have to rely on a statistical definition of the metabolic syndrome. In contrast to many others, it is a strength of our study that our definition is based on reference values derived from a large population-based sample of healthy children from a heterogeneous European population. The IDEFICS cohort forms a solid basis for a new-improved definition of MetS because it is the largest study of young children to date. This enables us to calculate robust estimates of the distribution of each risk factor considered in this definition. Moreover, we consequently applied age- and sex-specific cutoffs that take into account the physiological development characteristic of the relevant age group rather than applying fixed cutoffs derived from adult populations. Our approach leads to a more balanced contribution of each of the components to the overall makeup of MetS.

The IDEFICS cohort provides the opportunity of assessing the prevalence of MetS in young, mostly prepubertal children where the large sample size, the application of highly standardised measurements and the spread across Europe are particular strengths. The largest study available before included only three countries and was restricted to 1604 10-year-old and 1589 15 -year-old children. ${ }^{44}$

\section{CONCLUSIONS}

According to the various definitions of pediatric MetS used in our analyses, we classify a non-negligible proportion of prepubertal children as being affected. It has been observed that children with metabolic syndrome have an increased risk of cardiovascular diseases in adulthood. ${ }^{51}$ It is therefore of clinical relevance to identify those children who are at risk as early in childhood as possible, as they would probably benefit from lifestyle modifications. For this purpose, a definition is needed that guides clinical practice. However, the existing definitions of pediatric metabolic syndrome lead to inconsistent results, leaving clinicians without clear directions for risk assessment and diagnosis. This situation may be alleviated by our newly proposed definition because it gives more balanced weights to the different components of MetS and stresses the importance of adiposity as a risk factor for cardiometabolic disorders later in life. We hope that our newly proposed definition will help to improve clinical practice.

The continuous MetS score we developed should not be considered as competing with the proposed definition of MetS: rather than guiding clinical practice the score may serve as a useful tool in pediatric research and the evaluation of interventions. While clear definitions and simple cutoffs are needed for clinical practice, the continuous score corresponds better to the fact that MetS refers to a complex concept where we are dealing with predictors of risk that lie on a continuous scale and interact in complex ways. The metabolic syndrome is not a disease but a cluster of metabolic disorders. We should therefore be aware of the fact that every attempt to define thresholds is an arbitrary reduction of a complex reality behind it.

\section{CONFLICT OF INTEREST}

The authors declare no conflict of interest.

\section{ACKNOWLEDGEMENTS}

This work was done as part of the IDEFICS study (www.idefics.eu). We gratefully acknowledge the financial support of the European Community within the Sixth RTD Framework Programme Contract No. 016181 (FOOD). We thank the IDEFICS children and their parents for participating in this extensive examination. We are grateful for the support by school boards, headmasters and communities. We are also grateful to 
the Volkswagen Foundation financially supporting the production of this supplement. LL has received grant support from VR, FORTE and FORMAS (research councils in Sweden).

\section{STATEMENT OF ETHICS}

We certify that all applicable institutional and governmental regulations concerning the ethical use of human volunteers were followed during this research. Approval by the appropriate Ethics Committees was obtained by each of the eight centres doing the field work. Study children did not undergo any procedure before both they and their parents had given consent for examinations, collection of samples, subsequent analysis and storage of personal data and collected samples. Study subjects and their parents could consent to single components of the study while abstaining from others.

\section{DISCLAIMER}

The information in this document reflects the authors' view and is provided as is.

\section{REFERENCES}

1 Lozano R, Naghavi M, Foreman K, Lim S, Shibuya K, Aboyans V et al. Global and regional mortality from 235 causes of death for 20 age groups in 1990 and 2010: a systematic analysis for the Global Burden of Disease Study 2010. Lancet 2012; 380: 2095-2128.

2 Joshi $\mathrm{P}$, Islam S, Pais $\mathrm{P}$, Reddy S, Dorairaj $\mathrm{P}$, Kazmi $\mathrm{K}$ et al. Risk factors for early myocardial infarction in South Asians compared with individuals in other countries. JAMA 2007; 297: 286-294.

3 O'Donnell MJ, Xavier D, Liu L, Zhang H, Chin SL, Rao-Melacini P et al. Risk factors for ischaemic and intracerebral haemorrhagic stroke in 22 countries (the INTERSTROKE study): a case-control study. Lancet 2010; 376: 112-123.

4 May AL, Kuklina EV, Yoon PW. Prevalence of cardiovascular disease risk factors among US adolescents, 1999-2008. Pediatrics 2012; 129: 1035-1041.

5 Webber LS, Voors AW, Srinivasan SR, Frerichs RR, Berenson GS. Occurrence in children of multiple risk factors for coronary artery disease: the Bogalusa heart study. Prev Med 1979; 8: 407-418.

6 Chu NF, Rimm EB, Wang DJ, Liou HS, Shieh SM. Clustering of cardiovascular disease risk factors among obese schoolchildren: the Taipei Children Heart Study. Am J Clin Nutr 1998; 67: 1141-1146.

7 Chen W, Srinivasan SR, Elkasabany A, Berenson GS. Cardiovascular risk factors clustering features of insulin resistance syndrome (Syndrome $\mathrm{X}$ ) in a biracial (Black-White) population of children, adolescents, and young adults: the Bogalusa Heart Study. Am J Epidemiol 1999; 150: 667-674.

8 Moreno LA, Pineda I, Rodríguez G, Fleta J, Giner A, Juste MG et al. Leptin and metabolic syndrome in obese and non-obese children. Horm Metab Res 2002; 34 394-399.

9 Grundy SM, Cleeman JI, Daniels SR, Donato KA, Eckel RH, Franklin BA et al. American Heart Association; National Heart, Lung, and Blood Institute. Diagnosis and management of the metabolic syndrome: an American Heart Association/ National Heart, Lung, and Blood Institute Scientific Statement. Circulation 2005; 112: $2735-2752$

10 Alberti KG, Zimmet P, Shaw J, IDF Epidemiology Task Force Consensus Group. The metabolic syndrome-a new worldwide definition. Lancet 2005; 366: 1059-1062.

11 Csábi G, Török K, Jeges S, Molnár D. Presence of metabolic cardiovascular syndrome in obese children. Eur J Pediatr 2000; 159: 91-94.

12 Brambilla P, Lissau I, Flodmark C-E, Moreno LA, Widhalm K, Wabitsch M et al. Metabolic risk-factor clustering estimation in children: to draw a line across pediatric metabolic syndrome. Int J Obes (Lond) 2007; 31: 591-600.

13 Olza J, Gil-Campos M, Leis R, Bueno G, Aguilera CM, Valle M et al. Presence of the metabolic syndrome in obese children at prepubertal age. Ann Nutr Metab 2011, 58: $343-350$.

14 Mellerio H, Alberti C, Druet C, Capelier F, Mercat I, Josserand E et al. Nove modeling of reference values of cardiovascular risk factors in children aged 7 to 20 years. Pediatrics 2012; 129: e1020-e1029.

15 Ahrens W, Bammann K, Siani A, Buchecker K, De Henauw S, lacoviello L et al. IDEFICS Consortium. The IDEFICS cohort: design, characteristics and participation in the baseline survey. Int J Obes (Lond) 2011; 35: S3-S15.

16 Nagy $P$, Kovacs E, Moreno LA, Veidebaum T, Tornaritis $M$, Kourides $Y$ et al. Percentile reference values for anthropometric body composition indices in European children from the IDEFICS study. Int J Obes (Lond) 2014; 38(Suppl 2): S15-S25.
17 Barba G, Buck C, Bammann K, Hadjigeorgiou C, Hebestreit A, Mårild S et al. Blood pressure reference values for European non-overweight school children: The IDEFICS study. Int J Obes (Lond) 2014; 38(Suppl 2): S48-S56.

18 De Henauw S, Michels N, Vyncke K, Hebestreit A, Russo P, Intemann T et al. Blood lipids among young children in Europe: results from the European IDEFICS study. Int J Obes (Lond) 2014; 38(Suppl 2): S67-S75.

19 Peplies J, Jiménez-Pavón D, Savva SC, Buck C, Günther K, Fraterman A et al. Percentiles of fasting serum insulin, glucose, $\mathrm{HbA} 1 \mathrm{c}$ and HOMA-IR in pre-pubertal normal-weight European children from the IDEFICS cohort. Int J Obes (Lond) 2014; 38(Suppl 2): S39-S47.

20 Eisenmann JC. On the use of a continuous metabolic syndrome score in pediatric research. Cardiovasc Diabetol 2008; 7: 17.

21 Pandit D, Chiplonkar S, Khadilkar A, Kinare A, Khadilkar V. Efficacy of a continuous metabolic syndrome score in Indian children for detecting subclinical atherosclerotic risk. Int J Obes (Lond) 2011; 35: 1318-1324.

22 Andersen LB, Harro M, Sardinha LB, Froberg K, Ekelund U, Brage S et al. Physical activity and clustered cardiovascular risk in children: a cross-sectional study (The European Youth Heart Study). Lancet 2006; 368: 299-304.

23 Bel-Serrat S, Mouratidou T, Jiménez-Pavón D, Huybrechts I, Cuenca-García M, Mistura $L$ et al. Is dairy consumption associated with low cardiovascular disease risk in European adolescents? Results from the HELENA Study. Pediatr Obes 2013. doi10.1111/j.2047-6310.2013.00187.x.

24 Bel-Serrat S, Mouratidou T, Börnhorst C, Peplies J, De Henauw S, Marild S et al. Food consumption and cardiovascular risk factors in European children: the IDEFICS study. Pediatr Obes 2013; 8: 225-236.

25 Marfell-Jones M, Olds T, Stewart A, Carter L. International Standards for Anthropometric Assessment. International Society for the Advancement of Kinanthropometry: Potchefstroom, South Africa, 2006.

26 Cole TJ, Lobstein T. Extended international (IOTF) body mass index cut-offs for thinness, overweight and obesity. Pediatr Obes 2012; 7: 284-294.

27 Alpert BS. Validation of the Welch Allyn spot vital signs blood pressure device according to the ANSI/AAMI SP10: 2002. Accuracy and cost-efficiency successfully combined. Blood Press Monit 2007; 12: 345-347.

28 National Blood Pressure Education Working Group on High Blood Pressure in Children and Adolescents. The Fourth report on the diagnosis, evaluation and treatment of high blood pressure in children and adolescents: a working group report from the National High Blood Pressure Education Program. Pediatrics 2004, 114: 555-576.

29 Panz VR, Raal FJ, Paiker J, Immelman R, Miles H. Performance of the CardioChek PA and Cholestech LDX point-of-care analysers compared to clinical diagnostic laboratory methods for the measurement of lipids. Cardiovasc J S Afr 2005; 16: 112-117.

30 Peplies J, Guenther K, Bammann K, Fraterman A, Russo P, Veidebaum T et al. on behalf of the IDEFICS consortium. Influence of sample collection and preanalytical sample processing on the analyses of biological markers in the European multicentre study IDEFICS. Int J Obes (Lond) 2011; 35: S104-S112.

31 Matthews DR, Hosker JP, Rudenski AS, Naylor BA, Treacher DF, Turner RC et al. Homeostasis model assessment: insulin resistance and beta-cell function from fasting plasma glucose and insulin concentrations in man. Diabetologia 1985; 28: 412-419.

32 Suling M, Hebestreit A, Peplies J, Bammann K, Nappo A, Eiben G et al. Design and results of the pretest of the IDEFICS study. Int J Obes (Lond) 2011; 35: S30-S44.

33 Stomfai S, Bammann K, De Henauw S, Kovács É, Marild S, Moreno LA et al. Intra- and inter-observer reliability in anthropometric measurements in children. Int J Obes (Lond) 2011; 35: S45-S51.

34 Cook S, Weitzman M, Auinger P, Nguyen M, Dietz WH. Prevalence of a metabolic syndrome phenotype in adolescents: findings from the third National Health and Nutrition Examination Survey, 1988-1994. Arch Pediatr Adolesc Med 2003; 157: 821-827.

35 Viner RM, Segal TY, Lichtarowicz-Krynska E, Hindmarsh P. Prevalence of the insulin resistance syndrome in obesity. Arch Dis Child 2005; 90: 10-14.

36 Zimmet $\mathrm{P}$, Alberti KG, Kaufman F, Tajima N, Silink M, Arslanian S et al. The metabolic syndrome in children and adolescents-an IDF consensus report. Pediatr Diabetes 2007; 8: 299-306.

$37 \mathrm{Li} \mathrm{C}$, Ford ES, Mokdad AH, Cook S. Recent trends in waist circumference and waist-height ratio among US children and adolescents. Pediatrics 2006; 118 e1390-e1398.

38 Cole TJ, Bellizzi MC, Flegal KM, Dietz WH. Establishing a standard definition for child overweight and obesity worldwide: international survey. BMJ 2000; 320: $1240-1243$

39 Hickman TB, Briefel RR, Carroll MD, Rifkind BM, Cleeman الـ Maurer KR et al. Distributions and trends of serum lipid levels among United States children and adolescents ages 4-19 years: data from the Third National Health and Nutrition Examination Survey. Prev Med 1998; 27: 879-890.

40 Tamimi W, Albanyan E, Altwaijri Y, Tamim H, Alhussein F. Age-and gender-specific reference intervals for fasting blood glucose and lipid levels in school children 
measured with Abbott Architect c8000 Chemistry Analyzer. Indian J Clin Biochem 2012; 27: 141-146.

41 Stasinopoulos DM, Rigby RA. Generalized additive models for location scale and shape (GAMLSS). J Stat Softw 2007; 23: 1-46.

42 Cole TJ, Stanojevic S, Stocks J, Coates AL, Hankinson JL, Wade AM et al. Age- and size-related reference ranges: a case study of spirometry through childhood and adulthood. Stat Med 2009; 28: 880-898.

43 Landis JR, Koch GG. The measurement of observer agreement for categorical data. Biometrics 1977; 33: 159-174.

44 Ekelund U, Anderssen S, Andersen LB, Riddoch CJ, Sardinha LB, Luan J et al. Prevalence and correlates of the metabolic syndrome in a population-based sample of European youth. Am J Clin Nutr 2009; 89: 90-96.

45 Dubose KD, Stewart EE, Charbonneau SR, Mayo MS, Donnelly JE. Prevalence of the metabolic syndrome in elementary school children. Acta Pædiatr 2006; 95: 1005-1011.

46 Prince RL, Kuk JL, Ambler KA, Dhaliwal J, Ball GD. Predictors of metabolically healthy obesity in children. Diabetes Care 2014; 35: 1462-1468.

47 Sen Y, Kandemir N, Alikasifoglu A, Gonc N, Ozon A. Prevalence and risk factors of metabolic syndrome in obese children and adolescents: the role of the severity of obesity. Eur J Pediatr 2008; 167: 1183-1189.
48 Zhu H, Yan W, Ge D, Treiber FA, Harshfield GA, Kapuku G et al. Relationships of cardiovascular phenotypes with healthy weight, at risk of overweight, and overweight in US youths. Pediatrics 2008; 121: 115-122.

49 Magnussen CG, Koskinen J, Chen W, Thomson R, Schmidt MD, Srinivasan SR et al. Pediatric metabolic syndrome predicts adulthood metabolic syndrome, subclinical atherosclerosis, and type 2 diabetes mellitus but is no better than body mass index alone: the Bogalusa Heart Study and the Cardiovascular Risk in Young Finns Study. Circulation 2010; 122: 1604-1611.

$50 \mathrm{Chi} \mathrm{CH}$, Wang Y, Wilson DM, Robinson TN. Definition of metabolic syndrome in preadolescent girls. J Pediatr 2006; 148: 788-792.

51 Morrison JA, Friedman LA, Gray-McGuire C. Metabolic syndrome in childhood predicts adult cardiovascular disease 25 years later: the Princeton Lipid Research Clinics Follow-up Study. Pediatrics 2007; 120: 340-345.

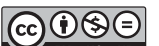

This work is licensed under a Creative Commons AttributionNonCommercial-NoDerivs 4.0 International License. The images or other third party material in this article are included in the article's Creative Commons license, unless indicated otherwise in the credit line; if the material is not included under the Creative Commons license, users will need to obtain permission from the license holder to reproduce the material. To view a copy of this license, visit http:// creativecommons.org/licenses/by-nc-nd/4.0/

\section{APPENDIX A}

Appendix A. Example: age- and sex-standardised z-scores and corresponding additive metabolic syndrome score of four children of the IDEFICS cohort

\begin{tabular}{|c|c|c|c|c|c|c|c|c|c|c|c|c|c|c|c|c|c|c|c|}
\hline \multirow{3}{*}{ Subject } & \multirow{3}{*}{$\frac{\text { Sex }}{\text { unit }}$} & \multirow{3}{*}{ Age } & \multicolumn{10}{|c|}{ Measured values } & \multicolumn{6}{|c|}{ Standardised residuals (z-scores) } & \multirow{3}{*}{$\begin{array}{l}\text { MetS } \\
\text { score }\end{array}$} \\
\hline & & & \multirow[t]{2}{*}{$W C$} & \multicolumn{2}{|c|}{$S B P$} & \multicolumn{2}{|c|}{$D B P$} & \multicolumn{2}{|c|}{$T R G$} & \multicolumn{2}{|c|}{$H D L$} & \multirow[t]{2}{*}{ HOMA } & \multirow[t]{2}{*}{$z_{W C}$} & \multirow[t]{2}{*}{$z_{S B P}$} & \multirow[t]{2}{*}{$z_{D B P}$} & \multirow[t]{2}{*}{$z_{T R G}$} & \multirow[t]{2}{*}{$z_{H D L}$} & \multirow[t]{2}{*}{$z_{\text {HOMA }}$} & \\
\hline & & & & $\mathrm{mm} \mathrm{Hg}$ & $k P a$ & $m m \mathrm{Hg}$ & $k P a$ & $m g d l^{-1}$ & $\mathrm{mmoll}^{-1}$ & $m g d l^{-1}$ & $\mathrm{mmoll}^{-1}$ & & & & & & & & \\
\hline 1 & $M$ & 6.5 & 59.5 & 109.0 & 14.5 & 67.5 & 9.0 & 48 & 0.54 & 38 & 0.98 & 0.65 & 1.66 & 0.85 & 0.72 & 0.29 & -1.22 & -0.15 & 3.05 \\
\hline 2 & $\mathrm{~F}$ & 5.8 & 60.4 & 92.0 & 12.3 & 52.5 & 7.0 & 50 & 0.56 & 52 & 1.34 & 1.59 & 2.20 & -0.96 & -1.77 & 0.17 & 0.10 & 1.39 & 2.26 \\
\hline 3 & $\mathrm{~F}$ & 5.2 & 53.0 & 94.0 & 12.5 & 58.0 & 7.7 & 45 & 0.51 & 61 & 1.58 & 1.00 & 0.58 & -0.51 & -0.81 & -0.73 & 0.88 & 0.68 & -0.07 \\
\hline 4 & $M$ & 5.5 & 57.5 & 99.0 & 13.2 & 66.0 & 8.8 & 78 & 0.88 & 45 & 1.16 & 0.99 & 1.64 & -0.13 & 0.59 & 1.15 & -0.54 & 0.71 & 3.43 \\
\hline
\end{tabular}

Sex: $F=$ girl, $M=$ boy; WC: waist circumference $(\mathrm{cm})$; SBP: systolic blood pressure ( $\mathrm{mm} \mathrm{Hg}$; $\mathrm{kPa}$ ); DBP: diastolic blood pressure (mm Hg; $\mathrm{kPa}$ ); TRG: triglycerides $\left(\mathrm{mg} \mathrm{dl}^{-1} ; \mathrm{mmoll}^{-1}\right)$; HDL: HDL cholesterol $\left(\mathrm{mg} \mathrm{dl}^{-1} ; \mathrm{mmoll}^{-1}\right)$; HOMA: homeostasis model assessment of insulin resistance; zvar: $\mathrm{z}$-score of the corresponding variable; MetS score: $\mathrm{z}_{\mathrm{WC}}+\left(\mathrm{z}_{\mathrm{SBP}}+\mathrm{z}_{\mathrm{DBP}}\right) / 2+\left(\mathrm{z}_{\mathrm{TRG}}-\mathrm{Z}_{\mathrm{HDL}}\right) / 2+\mathrm{z}_{\mathrm{HOMA}}$ 
APPENDIX B

Appendix B. Age- and sex-specific cut-offs for the two proposed definitions of metabolic syndrome with the 90th percentile (P90) corresponding to the monitoring level and the 95th percentile (P95) corresponding to the action level

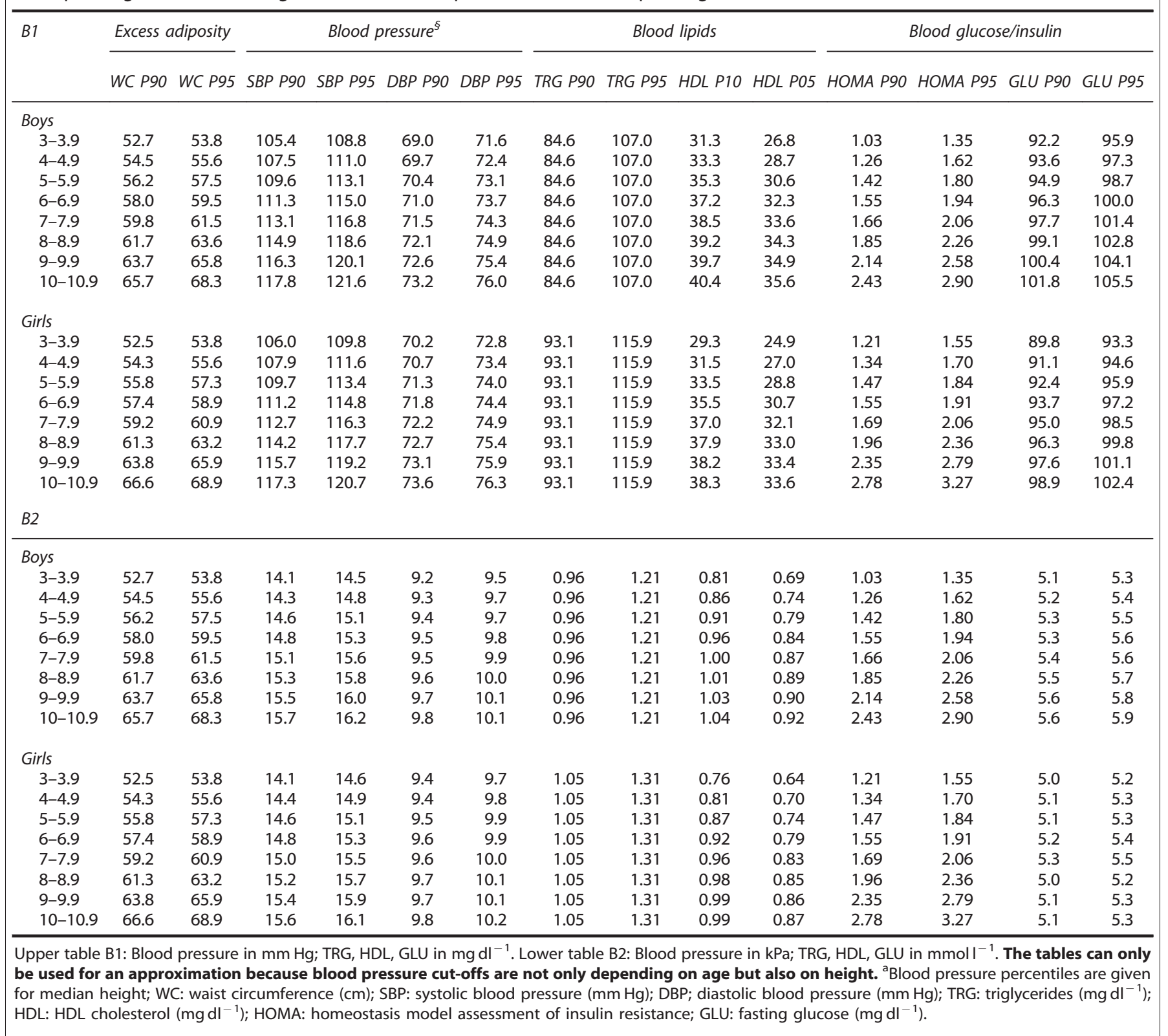

